REVIEW ARTICLE

\title{
Fluoride and hardness in groundwater of tropical regions - review of recent evidence indicating tissue calcification and calcium phosphate nanoparticle formation in kidney tubules
}

\author{
C.B. Dissanayake and Rohana Chandrajith* \\ Department of Geology, Faculty of Science, University of Peradeniya, Peradeniya, Sri lanka
}

Received: 30/04/2019 ; Accepted: 03/07/2019

\begin{abstract}
In many tropical environments, groundwater has high fluoride concentrations in addition to other ions such as $\mathrm{Na}^{+}, \mathrm{Ca}^{2+}, \mathrm{Mg}^{2+}$ and $\mathrm{PO}_{4}^{3-}$. These ions interact with one another and this geochemistry has a direct bearing on the health of the population living in such terrains. In the majority of cases, it is the groundwater that is used for drinking and the input of the above mentioned ions into the body often results in diseases such as dental and skeletal fluorosis, chronic kidney disease, soft and hard tissue calcification. Even though the actual input of the above mentioned ions into the body from drinking water as against diet, may be low, as reported in some studies, it may be high in people living in tropical terrains where agricultural productivity and nutrition is low and where the consumption of such water is high.
\end{abstract}

Keywords: fluoride, ionic interactions, kidney tubules, apatite crystallization.

\section{INTRODUCTION}

Tropical regions which cover approximately $40 \%$ of the earth have some unique features in their geology, geochemistry and water quality. The climate plays a major role in bringing about these special features due to its extreme effects on rock weathering, nutrient depletion in soils, evaporation, evapotranspiration and concentration of many chemical species in groundwater. Interestingly, over 150 countries have at least half their landmass in the tropics and these countries represent more than $40 \%$ of the world's population of around 7.6 billion. The majority of these countries has poor agricultural productivity, water quality and associated health problems. Due to extreme changes in climate and rainfall, rock weathering is intense and soils are leached heavily. This results in poor agricultural productivity due to low nutrients (Fyfe et al., 1983). The groundwater composition changes markedly during wet and dry seasons and in extreme cases the dissolved ions could reach very high levels exceeding the WHO recommended values several fold. The intimate association of the tropical population with the immediate geoenvironment results in several "geochemical diseases" on account of their origin in the geological environment (Dissanayake and Chandrajith, 1999; Dissanayake and Chandrajith, 2009a). Under the tropical environmental conditions of high temperature, high rainfall alternating with very dry spells, element fractionation during rock weathering and soil formation result in heterogeneous distribution of chemical species in the geoenvironment. These geochemical provinces are unique in their chemistry and form an important facet of medical geology in tropical environments (Dissanayake, 1996; 2005a; Dissanayake and Chandrajith, 2009a; Chandrajith et al., 2011b).

Fluoride is generally found in excessive amounts in the groundwater of these countries (Dissanayake, 2005b) and has a marked impact on the health of the population resulting in dental and skeletal fluorosis. Harinarayan et al. (2006) have shown that evidences of chronic fluoride intoxication associated with renal tubular dysfunction focusing on the possibility that fluoride toxicity may be responsible for both bone and kidney disease. Renal function, especially glomerular filtration rate is very sensitive to fluoride exposure (Ando et al., 2001). In Sri Lanka, notably in some parts of the dry zone in the north central regions, a chronic kidney disease hitherto known as "of uncertain origin", persists in the areas of fluoriderich groundwater coupled with water with high calcium and magnesium levels (Dissanayake and Chandrajith, 2007).This paper attempts to highlight the importance of groundwater with high levels of $\mathrm{Ca}^{2+}, \mathrm{Mg}^{2+}, \mathrm{F}^{-}$and $\mathrm{PO}_{4}^{3-}$ used for drinking and its impact on the biogeochemical mechanisms leading to kidney tubular damage with the end result of chronic kidney disease (CKD).

\section{Geochemistry of fluoride in groundwater}

Fluorine is the most electronegative and chemically reactive element of all halides. It is highly reactive with all organic and inorganic substances, very often forming highly toxic compounds. It is abundant in silicate minerals at concentrations of about $650 \mathrm{mg} / \mathrm{kg}$ (Adriano, 2001). It has been shown that the geochemistry of the fluoride ion $\mathrm{F}^{-}$, (ionic radius $136 \mathrm{pm}$ ) is similar to that of the hydroxyl $\left(\mathrm{OH}^{-}\right)$ion (ionic radius $140 \mathrm{pm}$ ) and hence there can be easy exchange between them. Fluorapatite $\left[\mathrm{Ca}_{5}\left(\mathrm{PO}_{4}\right)_{3} \mathrm{~F}\right]$ and hydroxyapatite $\left[\mathrm{Ca}_{5}\left(\mathrm{PO}_{4}\right)_{3} \mathrm{OH}\right]$, are isomorphic end members of the solid solution series $\mathrm{Ca}_{5}\left(\mathrm{PO}_{4}\right)_{3}(\mathrm{OH}, \mathrm{F})$. Hydroxyapatite, however, is the main mineral phase of 
enamel in human teeth, a fact often used as an argument against the essentiality of fluoride to humans (Pauwels and Ahmed, 2007; Dissanayake and Chandrajith, 2009a). In general, the concentration of fluoride in groundwater is controlled by the solubility of $\mathrm{CaF}_{2}$, whereas the dissolution of $\mathrm{Ca}^{2+}$ in groundwater is controlled by the solubility of calcite and fluorite. The dissolution of calcite and fluorite is inversely proportional to each other, the activities of calcium, fluoride and carbonate being independent in groundwater (Rafique et al., 2009; Kim et al., 2012).

Due to the extreme changes of climate, weathering of rocks, minerals and degradation of soils takes place rapidly and passage of some chemical species into the aqueous medium takes place easily, thereby enriching the medium with abundant ions, a feature so typical of tropical environments. The leachability of fluoride from minerals such as carbonate concretions is controlled by $\mathrm{pH}$ of draining solutions, alkalinity, dissolved $\mathrm{CO}_{2}$ and the $\mathrm{pCO}_{2}$ in the soil (Figure 1). It is to be noted that the soil-water interaction and residence time of fluoride are two important factors that govern the fluoride concentration in water. Table 1 shows the average fluoride ranges in different types of water. The interaction dynamics of groundwater with rocks and minerals and associated fluoride concentration plays an important role and it has been noted that groundwater with long residence time is usually associated with deep aquifer systems and a slow groundwater movement as well (Figure 2) (Sivasankar et al., 2016).

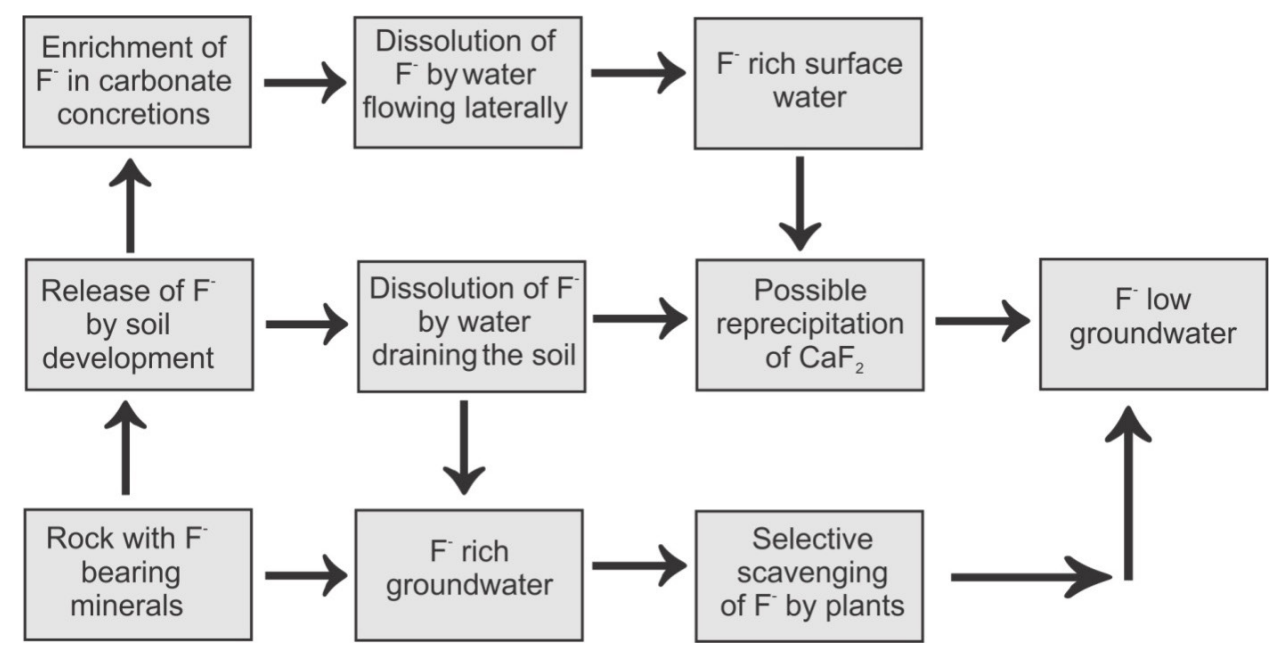

Figure 1: Mechanism for fluoride ingestion in arid and semi-arid areas(Modified from Ramesan and Rajagopalan, 1985).

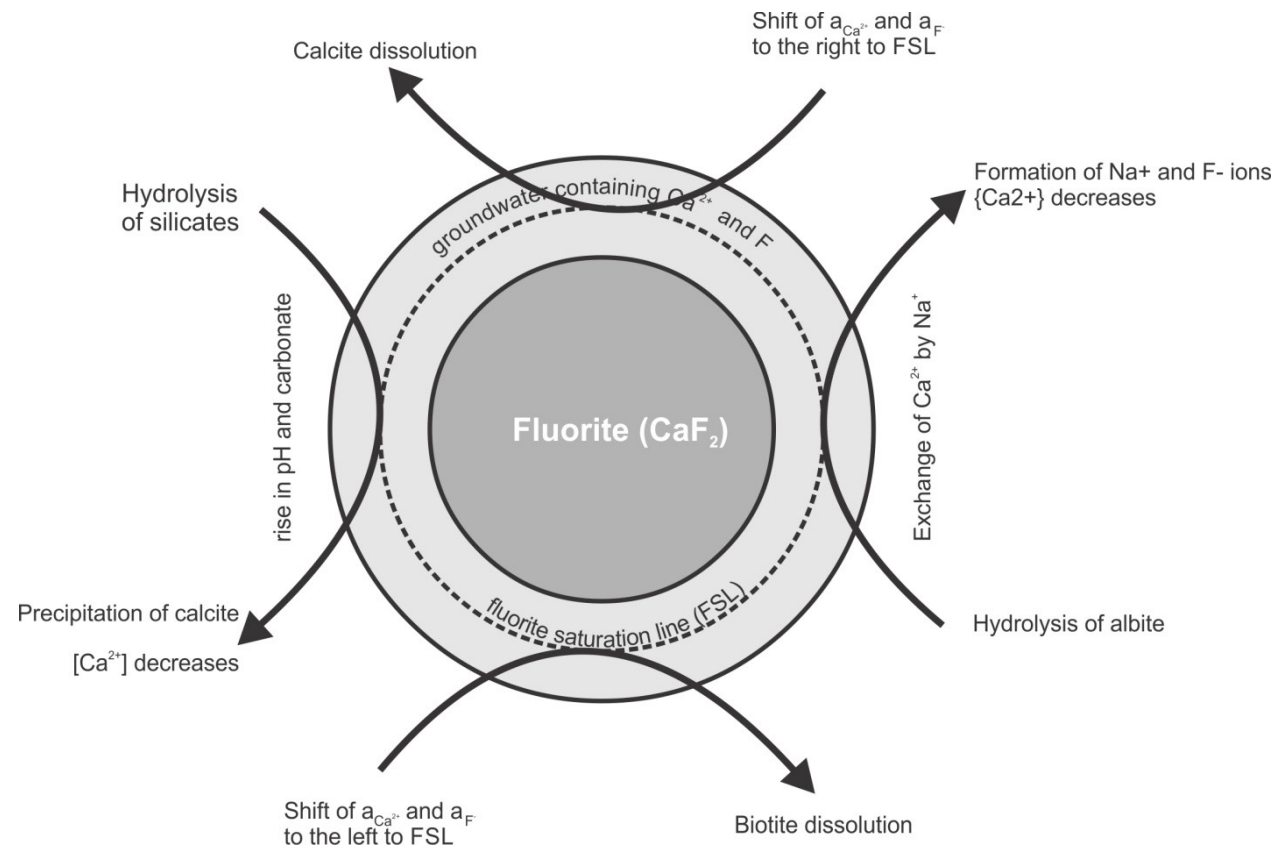

Figure 2: Interaction dynamics of fluoride in groundwater (after Sivasankar et al., 2016). 
Table 1: Fluoride contents in different environmental components (after (Edmunds and Smedley, 2013).

\begin{tabular}{ll}
\hline \multicolumn{1}{c}{ Source } & \multicolumn{1}{c}{ Range of fluoride $(\mathbf{m g} / \mathbf{L})$} \\
\hline Rainfall & $0.013-0.096$ \\
Surface waters (rivers) & $0.06-0.18$ \\
Surface waters in high fluoride regions & $0.6-1281$ \\
Soil water & $0.02-0.30$ \\
Geothermal springs & $0.4-330$ \\
Groundwater crystalline basement rocks & $<0.02-20$ \\
Groundwater volcanic rocks & $2.1-250$ \\
Groundwater sediments and sedimentary basins & $<0.1-29$ \\
\hline
\end{tabular}

\section{Fluoride as a nephrotoxin}

It is well known that excessive fluoride concentrations in the groundwater can lead to dental and skeletal fluorosis among the population living in such terrains (Dissanayake, 2005a; 2000b). The map showing the distribution of fluoride in the groundwater of Sri Lanka clearly shows that the highest concentrations of fluoride are found in the dry zone regions (Figure 3a). Dental fluorosis is quite common among population living in such areas (Figure 4). Interestingly, the prevalence of chronic kidney disease of unknown etiology $(\mathrm{CKDu})$ also coincides with the higher fluoride geochemical province (Figure 3b). Dissanayake (2005b), first suggested that it is the fluoride concentration and its interactions with other ions such as $\mathrm{Ca}^{2+}, \mathrm{Mg}^{2+}$ and $\mathrm{Na}^{2+}$ that could trigger the onset of CKDu in Sri Lanka. In his paper several important observations and suggestions had been made as follows;

a. All areas affected by the $\mathrm{CKDu}$ were located in the dry zone and within this zone, areas with higher groundwater fluoride correlated with locations of high CKDu prevalence. This important correlation paved the way for further studies. The Hydrogeochemical Atlas of Sri Lanka produced by Dissanayake and Weerasooriya (1985), had already demarcated the "fluoride belt" of Sri Lanka at the boundary of the dry zone and the intermediate climatic zone.

b. The groundwater was more saline with high electrical conductivity indicative of an abundance of total dissolved solids.

c. The dry zone soils, due to the effect of drought and evaporation, tend to accumulate salts in the soil which then enrich the groundwater with many cations.

The important suggestion made by Dissanayake (2005b), notably the interaction of groundwater fluoride with other cations as a probable causative process for the $\mathrm{CKDu}$, though doubted at first, gained gradual acceptance when further research studies were carried out with new data being published. It is now generally accepted that water hardness and fluoride together play a major role in the onset of CKDu (Dharmaratne, 2015).

The prediction of Dissanayake (2005b), "The abundance of high fluoride in all areas and dissolved solids in the groundwater, and the high saline nature of the water may well turn out to be a major factor in the incidence of $C R F$ ", is now gaining credence. Fluoriderich groundwater geochemistry, as shown by Dissanayake (2005b), is therefore of paramount importance in the study of the aetiology of CKDu.

The importance of fluoride as a geochemical marker for CKDuwas furtherdiscussed by DissanayakeandChandrajith (2017). It is known that the kidney, with the exception of the pineal gland, is exposed to high concentrations of fluoride than all other soft tissues in the human body. Damaged kidneys accumulate more fluoride resulting in further damage to kidney, bone and other organs (Connett, 2012). It has also been observed that those who suffer from CKD in tropical countries also have a tendency to develop bone disease, mainly skeletal fluorosis. Lantz et al. (1987) reported a case of fluoride intoxication related to potomania of Vichy water, a highly mineralized water containing 8.5 $\mathrm{mg} / \mathrm{L}$ of fluoride. They observed a relationship between osteosclerosis and end-stage renal failure and concluded that the long duration of high fluoride intake and the absence of other causes of renal insufficiency suggested a causal relationship between fluoride intoxication and renal failure. Fluoride has consistently been underestimated for its toxic effects mainly because of the proponents of water fluoridation emphasizing the supposed benefits of fluoride to dental health. At an optimum level, fluoride may have beneficial effects, but at higher concentrations, the detrimental effects notably in teeth, bones and kidneys are remarkably high (Çiftçioglu et al., 1999; Harinarayan et al., 2006). Significantly, even at low doses, fluoride is known to interact with cellular systems including oxidative stress and modulation of intracellular redox homeostasis and some others emphasizing the toxicity of fluoride to human beings (Cittanova et al., 1996). Fluoride could be more genotoxic at lower doses than at higher doses when ingested through drinking water (Podder et al., 2011). It should be remembered that the largest input of fluoride into the human body comes from drinking rather than diet and air. This fact is of extreme importance in tropical dry regions of the world where millions of people use fluoridebearing water as their drinking water source. It should however be mentioned that tea is a source of fluoride and this may provide an additional input to the human fluoride intake (Chandrajith et al., 2007). 


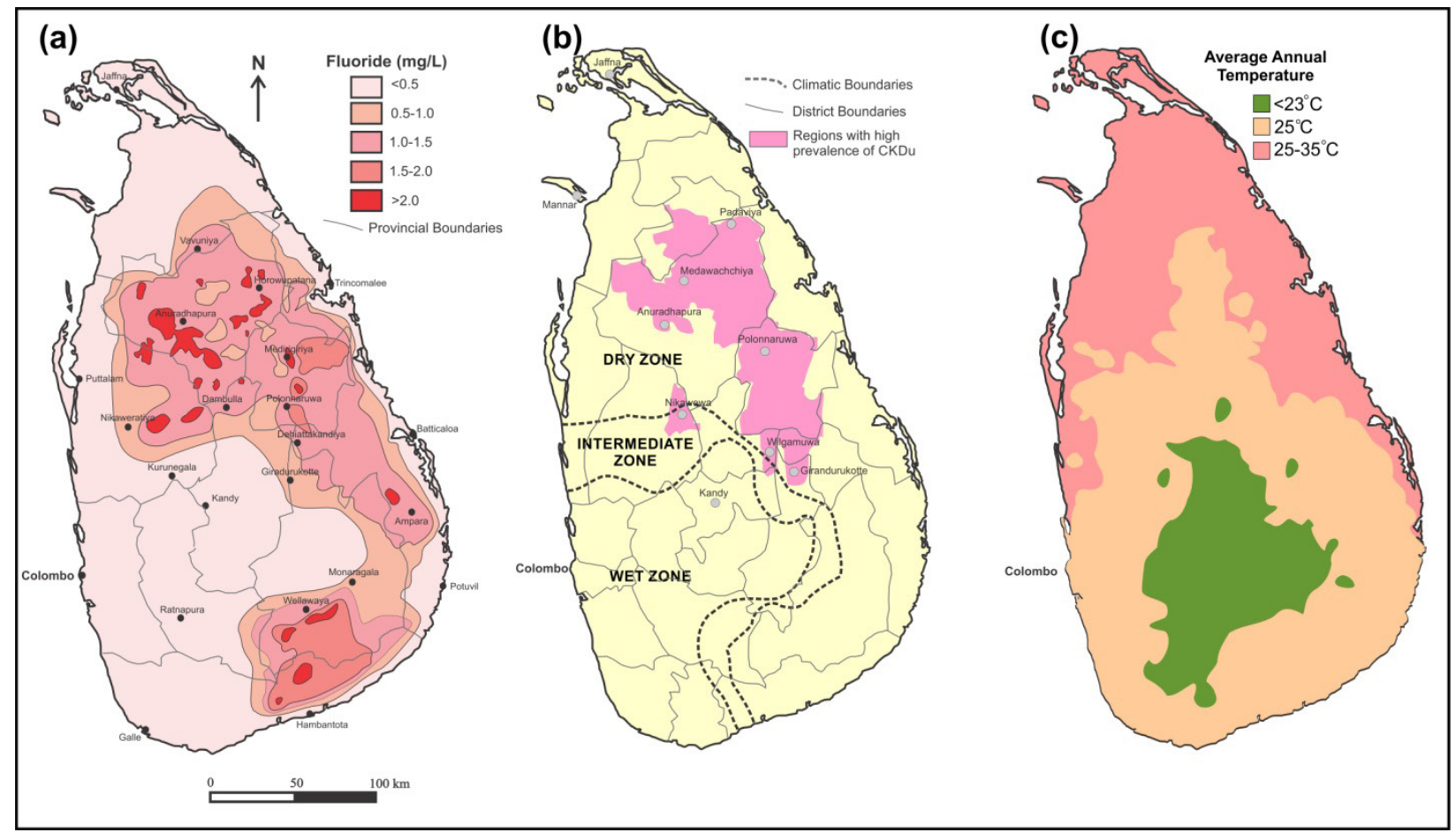

Figure 3:(a) Map showing the distribution of fluoride in groundwater (Chandrajith et al., 2012); (b) areas with high prevalence of endemic kidney diseases and (c) average temperature variation in Sri Lanka.

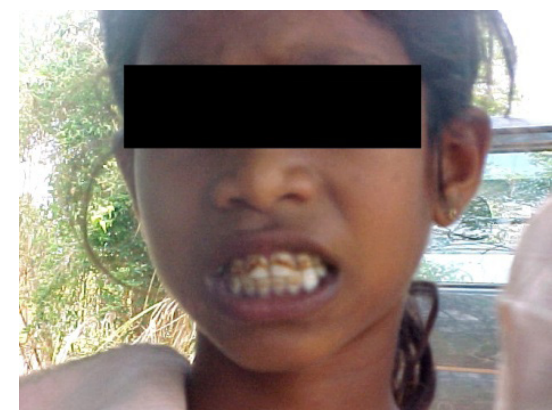

Figure 4: A case of dental fluorosis in Sri Lanka.

The determination of the exact dose of fluoride that is effective in the triggering of physiological imbalances and how other interactive chemical species such as $\mathrm{Na}^{+}$, $\mathrm{Ca}^{2+}$ and $\mathrm{Mg}^{2+}$ control the critical dose needs further extensive research (Dissanayake and Chandrajith, 2017). Experiments had been carried out in order to characterize some subcellular determinants of fluoride cytotoxicity and to determine whether sub-toxic fluoride exposure affects tubular cell vulnerability to superimposed ATP depletion and nephrotoxic attack (Zager and Iwata, 1997). They concluded that (a) fluoride induces dose-dependent cytotoxicity in cultured human proximal tubular cells, (b) this occurs via $\mathrm{Ca}^{2+}$ and phospholipase A2- (PLA2) dependent mechanisms, (c) partial cytosolic PLA2 depletion subsequently results and (d) sub-toxic fluoride exposure can acutely increase cell resistance to further attack.

Quadri et al. (2018) pointed out that in India alone, 21 out of 35 states has endemic fluorosis due to high fluoride contamination from groundwater. Kidneys are also known to be badly affected due to their susceptibility to fluoride toxicity and to their unique anatomy and function.
Children suffering from renal impairments also have some symptoms of dental and skeletal fluorosis suggesting a link between fluoride and renal anatomy/physiology (Quadri et al., 2018). A screening of 156 patients with childhood nephrotic syndrome, 32 of them had significantly high levels $(p<0.05)$ of fluoride in urine $\quad(4.01 \pm 1.83 \mathrm{mg} / \mathrm{L})$ and serum $(0.1 \pm 0.013 \mathrm{mg} / \mathrm{L})$. Various sub-cellular ultrastructural changes including nuclear disintegration, chromosome condensation, cytoplasmic ground substance lysis and endoplasmic reticulum blebbing were noted. Increased levels of apoptosis were also observed in the high fluoride group compared to the normal fluoride group.

The significance of the above mentioned observations may be applicable to the large number of CKDu patients in the dry zone of Sri Lanka. Dharmaratne (2015), noted the following features associated with the Sri Lankan CKDu;

- Fluoride excretion rate is considerably lower in children than adults, leading to renal damage of children living in areas with high fluoride.

- Adults who had renal damage due to fluoride in childhood are vulnerable to $\mathrm{CKDu}$ with continued consumption of 
Table 2: Fluoride (mg/L) and hardness $(\mathrm{mg} / \mathrm{L})$ in CKDu effected and no-effected regions (*calculated using Ca and $\mathrm{Mg}$ values).

\begin{tabular}{|c|c|c|c|}
\hline Region & Fluoride & Hardness & Reference \\
\hline \multicolumn{4}{|l|}{ CKDu regions } \\
\hline Girandurukotte & 0.64 & 217 & Chandrajith et al. (2011a) \\
\hline Nikawewa & 1.21 & 336 & $"$ \\
\hline Medawachchiya & 1.42 & 324 & $"$ \\
\hline Padaviya & 0.62 & 443 & $"$ \\
\hline Kebithigollawa & 1.00 & 345 & Lapegue (2000) \\
\hline Gomarankadawala & 1.00 & 466 & $"$ \\
\hline $5 \mathrm{CKDu}$ endemic regions & 1.00 & $215^{*}$ & Rango et al. (2015) \\
\hline Medawachchiya & 0.97 & 230 & Wasana et al. (2016) \\
\hline Medawachchiya/Maderigiriya & 0.60 & $223^{*}$ & Levine et al. (2016) \\
\hline Girandurukotte & 0.73 & 148 & Wickramarthana et al. (2017) \\
\hline Wilgamuwa & 1.48 & 279 & " \\
\hline Nikawewa & 1.12 & 428 & $"$ \\
\hline \multicolumn{4}{|l|}{ Non-CKDu regions } \\
\hline 3 non-endemic regions & 0.05 & $19.4^{*}$ & Rango et al. (2015) \\
\hline Matale & 0.20 & $259 *$ & Chandrajith et al. (2015) \\
\hline Haguranketha & 0.25 & 79.9 & Abeywickarama et al. (2016) \\
\hline Panama & 0.44 & 6.69 & Chandrajith et al. (2014) \\
\hline Jaffna & 0.38 & $503 *$ & Chandrajith et al. (2016) \\
\hline Mannar & 0.41 & $476^{*}$ & Bandara et al. (2018) \\
\hline
\end{tabular}

water from the same source.

- Patients with chronic renal insufficiency are at an increased risk of chronic fluoride toxicity.

- High content of fluoride in groundwater paves the way to excess fluoride in local food crops, consequently adding more fluoride to the systems of the consumers.

- People who work outdoors for prolonged periods consume excess water and tea, and are subjected to additional doses of fluoride in their system.

\section{Water hardness and kidney disease}

A noteworthy feature of the spatial distribution of $\mathrm{CKDu}$ in Sri Lanka is its prevalence in regions of high fluoride groundwater and high water hardness (Chandrajith et al., 2011a; Chandrajith et al., 2011b) (Table 2). Most natural water supplies in the dry zone of Sri Lanka contain dissolved calcium and magnesium carbonates and silicates (Dissanayake and Chandrajith, 1999). The interactions of fluoride with $\mathrm{Ca}^{2+}, \mathrm{Mg}^{2+}, \mathrm{PO}_{4}^{3-}$ and $\mathrm{Na}^{+}$appear to have a controlling effect on the onset of CKDu, depending on their dosage (Chandrajith et al., 2011a) and saturation factors. Both geochemical and biochemical influence by these chemical species do exert a marked effect on the etiology of the kidney disease. While water hardness alone could not be a causative agent for $\mathrm{CKDu}$, their combined and synergistic effect, mainly due to the controlling effects on solubility and precipitation, could however, be a rate determining step in the mechanism of the disease onset.

Several studies have shown an inverse relationship between drinking water magnesium level and heart disease (Rylander et al., 1991; Yang, 1998; Leurs et al., 2010;
Knezović et al., 2014) although its effect on kidney disease remains to be studied in greater detail. The increase of $\mathrm{Ca}^{2+} / \mathrm{Mg}^{2+}$ ratio in drinking water is also attributed to the occurrence of urolithiasis (Yang et al., 2016). The studies of Dharma-wardana et al. (2015) and Dharma-wardana (2018) highlighted the importance of groundwater ionicity noting that fluoride may contribute to $\mathrm{CKDu}$ by its high rank in the Hofmeister series (Zhang and Cremer, 2006) for denaturing of proteins of the kidney membrane. They also suggested that while the increase of hardness (below a threshold) correlates with good health, any ionicity increase above a threshold would correlate with disease.

Wickramarathna et al. (2017), who studied the etiological factors associated with CKDu in the dry zone of Sri Lanka observed that hardness reached values as high as $516 \mathrm{mg} / \mathrm{L}$ in some groundwater in affected regions. The mean hardness of groundwater in all samples taken during the pre-monsoon period was $181 \mathrm{mg} / \mathrm{L}$ indicating very hard water. Their studies clearly indicated a close association of CKDu with the synergistic effect of high water hardness and high fluoride in groundwater. The importance of high water hardness in the etiology of CKDu was also highlighted by Herath et al. (2017). They observed that $26.9 \%$ of well water in dry zone of Sri Lanka was soft, $15.0 \%$ moderately hard, $15.8 \%$ hardand $42.2 \%$ very hard. This close association of fluoride with water hardness further emphasizes the importance of the latter in the etiology of $\mathrm{CKDu}$. The climate change impact is expected to enhance fluoride accumulations in groundwater, in particular through the decrease of rainfall and increase of evaporation (Pauwels et al., 2011). The non-prevalence of $\mathrm{CKDu}$ in the northern regions of Sri Lanka underlain 
by limestones, possibly due to the non-availability of fluoride caused by the precipitation of $\mathrm{CaF}_{2}$ in view of the abundance of calcium. Further, the hard metamorphic rocks carrying fluoride-bearing minerals are only found at considerable depths.

\section{Effect of calcium, magnesium and phosphate ions on CKDu}

Given the scenario where groundwater fluoride, water hardness and phosphates are high, and also in view of the fact that the vast majority of people in tropical dry terrains use this groundwater as their drinking water source, $\mathrm{Ca}^{2+}$, $\mathrm{Mg}^{2+}$ and $\mathrm{PO}_{4}^{3-}$ assume importance in health. Blaine et al. (2014) reviewed the renal control of the above mentioned chemical species in view of their importance in many biological and cellular functions, with kidneys playing a central role in the homeostasis of the ions. Renal excretion balances the gastrointestinal absorption when the contents of these ions decline significantly, gastrointestinal absorption, bone resorption and renal tubular reabsorption increase to normalize their levels. Renal regulation becomes an important determinant of plasma ion concentration since it occurs through glomerular filtration and tubular readsorption and/or secretion. The fine adjustment of urinary excretion to balance the net intake maintains the whole body balance of $\mathrm{Ca}^{2+}, \mathrm{Mg}^{2+}$ and $\mathrm{PO}_{4}^{3-}$ under physiological conditions. In the case of Sri Lanka, $\mathrm{PO}_{4}{ }^{3-}$ levels in groundwater are high due to the alarmingly excessive application of phosphate fertilizers (Dissanayake and Chandrajith, 2009b; Rubasinghe et al., 2015). Since the drinking water of the affected population of the dry zone of Sri Lanka consume large quantities of such water, their body burden of the ions may be excessive and which may have a significant impact on kidney tubular damage. This may not be too significant in temperate countries where the input if these ions may be much lower.

\section{Magnesium as a neglected element in CKD}

It has been clearly stated above that water hardness and fluoride levels in the groundwater in combination with phosphates could be a cause for $\mathrm{CKDu}$ in tropical dry terrains. While the importance of calcium in kidney diseases has been discussed at length in many studies, magnesium, which is also an integral component of hard water has been grossly underestimated for its role in the etiology of CKDu. Magnesium plays a major role in cardioprotectivity and shows an antagonistic biochemical behavior towards calcium. The $\mathrm{Ca}^{2+} / \mathrm{Mg}^{2+}$ ratio in both groundwater and in the body tissues appear to be of paramount importance in controlling the homeostasis of these two species. The high levels of drinking water fluoride can increase the levels of two kidney damage markers, $\mathrm{N}$-acetylglucosaminidase (NAG) and $\gamma$-glutamyltransferase $(\gamma-\mathrm{GT})$ in urine in children (Xiong et al., 2007). The CKDu of the dry zone of Sri Lanka is a slow progressing disease and the investigations on histopathology of kidney patients indicated a tubulointerstitial disease present mainly as focal to diffuse fibrosis, accompanied by varying degrees of sclerotic vascular lesions resulting in high frequency of glomerular sclerosis and collapse (Nanayakkara et al.,
2014)

Magnesium is known to play a very important role in over 300 enzymatic reactions and transport processes and synthesis of proteins DNA and RNA (De Francisco and Rodríguez, 2013). They showed that Mg deficiency is a risk factor for several common metabolic diseases, whereas $\mathrm{Mg}$ supplementation and mild hypermagnesia might have beneficial effects in CKD patients with regard to calcification and mortality. Significantly, in CKD patients, cardiovascular disease is the leading cause of death (Foley et al., 1998). Patients with CKD undergoing dialysis have 2 to 5 fold more coronary artery calcification than agematched individuals. The calcifications take place in the intimal and medial vessel layer and this plays a major role in cardiovascular disease and mortality in CKD patients (De Francisco and Rodríguez, 2013).

The input of $\mathrm{Ca}^{2+}$ and $\mathrm{Mg}^{2+}$ into the body in the population living in tropical dry regions and consuming hard water is not known to any degree of certainty, though it can be expected that in view of the high frequency of consumption of hard water, the input of $\mathrm{Ca}^{2+}$ and $\mathrm{Mg}^{2+}$ into the body may be high. This needs further study, supported by geochemical mapping of $\mathrm{Ca}^{2+}$ and $\mathrm{Mg}^{2+}$ and their ratios in the groundwater. In the dry zone of Sri Lanka where the CKDu prevalence is high, the average $\mathrm{Mg}^{2+}$ content in the groundwater is $35.7 \mathrm{mg} / \mathrm{L}$ as compared to the $\mathrm{Mg}^{2+}$ content of $9.65 \mathrm{mg} / \mathrm{L}$ in wet zone where the $\mathrm{CKDu}$ incidence is insignificant (Rubasinghe et al., 2015). This indicates the need for a detailed study of $\mathrm{Mg}$ and its role in CKDu.

\section{Nanocrystal formation in kidney tubules}

The geochemistry of the groundwater with high concentrations of $\mathrm{Ca}^{2+}, \mathrm{Mg}^{2+}, \mathrm{F}^{-}$and $\mathrm{PO}_{4}^{3-}$ and the large consumption of such water is conducive for the precipitation of nanocrystals of calcium phosphate as either hydroxyapatite or fluorapatite or as its mixtures. These nanocrystals of calcium phosphate are formed in pathological calcifications as well as during stone formation. Even though many theories have been put forward as to how the nanocrystals form in the human tissues (Miller et al., 2004), the exact mechanism is still being debated. Yiu et al. (2015) reviewed the mechanism that cause biocalcification. They discussed a recent computer model indicating a possible cause of spontaneous tubular calcium phosphate crystal formation, specifically at the descending loop of Henle, due to an increase in plasma phosphate, or a decrease in phosphate fractional re-adsorption in the proximal tubule (Robertson, 2015). They also a report a study by Linnes et al. (2013), who showed a greater incidence of tubular plugging, in which some stone formers (brushite and apatite) exhibited severe plugging, calcium phosphate supersaturation being a major factor associated with plug formation. A study by Martel et al. (2014) has shown that mineralizing tissues contain polyphosphate nanoparticles that may serve as a source of inorganic phosphate for apatite formation following treatment with alkaline phosphatase. Martel et al. (2014) believe that monitoring the level of apatite particles found in body fluids may allow us to determine the general state of vascular calcification and predict the progression of 
certain pathologies like end-stage renal disease.

The human kidney tissues obtained from end-stage chronic kidney disease or renal cancer patients contained round, multilamellar mineral particles of 50 to $1500 \mathrm{~nm}$ whereas no particles were observed in healthy controls (Wong et al., 2015). They observed that these nanoparticles were composed of polycrystalline calcium phosphate similar to the mineral found in bones. The nanoparticles were deposited in the extracellular matrix surrounding the convoluted tubules, collecting ducts and loops of Henle as well as within the cytoplasm of tubule delineation cells (Figure 5). Recent studies on calcium phosphate nanoparticle formation in kidney tubules (Figure 6) open up new avenues of research on the impact of groundwater chemistry on chronic kidney diseases in tropical geoenvironments where the water is abundant in dissolved solids including $\mathrm{Ca}^{2+}, \mathrm{Mg}^{2+}, \mathrm{PO}_{4}^{3-}, \mathrm{Na}^{+}$and $\mathrm{F}^{-}$, formation of nanocrystals with a higher fluoride content could be envisaged. For example, when drinking water has very high fluoride levels, a reaction can take place (Thole, 2011) as given below;

$\mathrm{Ca}_{5}\left(\mathrm{PO}_{4}\right)_{3} \mathrm{~F}+9 \mathrm{~F}^{-} \longrightarrow \mathrm{Ca}_{5} \mathrm{~F}_{10}+3 \mathrm{PO}_{4}^{3-}$

The calcium deca-fluoride so formed is very hard and brittle and is unsuitable for the bone structure and will certainly have a debilitating effect on the kidney.

The role of nanobacteria as nuclei for the formation of calcium phosphate nanoparticles has been studied extensively (Çiftçioglu et al., 1999; Cisar et al., 2000). Self-replicating nanobacteria and their association with calcium phosphate nanoparticle formation in kidney tubules, particularly in CKDu patients in tropical countries would pave the way for an entirely new biogeochemical pathway for kidney diseases.

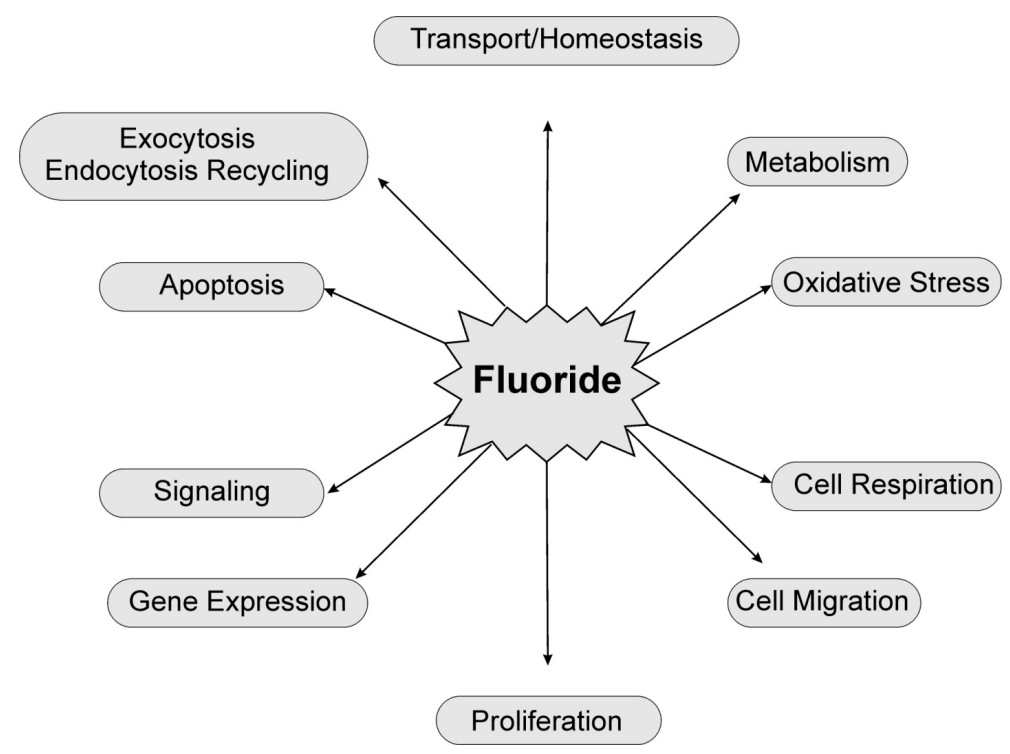

Figure 5: General scheme of the biological consequences of fluoride exposure on mammalian cells (after Barbier et al, 2010).

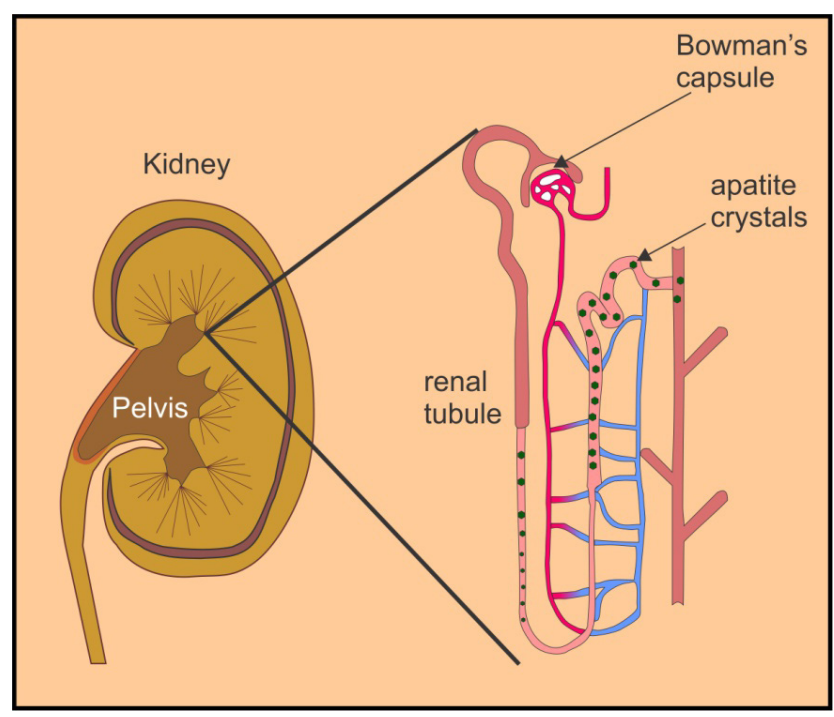

Figure 6: Calcium phosphate (apatite) deposition in kidney tubules. 


\section{CLIMATE CHANGE, WATER QUALITY AND CKD}

Climate change is a scientific fact and this has led to a significant rise of $0.80{ }^{0} \mathrm{C}-0.90{ }^{\circ} \mathrm{C}$ in global mean temperature over the last century. With ensuing heat waves and heat stress human health is increasingly affected directly as well as indirectly. One of the consequences of climate-related extreme heat exposure is dehydration and volume loss, leading to kidney ailments (Roncal-Jimenez et al., 2016). Heat stress and recurrent dehydration has been linked to the high prevalence of CKD of uncertain etiology, recognized in Central America, termed Mesoamerican nephropathy (Crowe et al., 2013; Glaser et al., 2016; Roncal-Jimenez et al., 2016). Several experimental and epidemiological studies have shown that the disease may be a type of heat stress nephropathy (HSN) and that this could be an example of a disease that is accelerated by global warming (Roncal-Jimenez et al., 2016).

Figure $3 c$ illustrates the relationship of Sri Lankan $\mathrm{CKDu}$ and heat distribution in the country. While the correlation of temperature and $\mathrm{CKDu}$ incidence is seen in many parts of the dry zone, some parts of Sri Lanka, notably the northern regions have little or no CKDu. This indicates that apart from heat stress, other factors such as groundwater geochemistry play a major role in the etiology of CKDu. A marked effect of climate change in the tropical environments is the change in water quality. The high evaporation rates increase the concentrations of many dissolved ions including $\mathrm{F}^{-}, \mathrm{Ca}^{2+}, \mathrm{Na}^{+}, \mathrm{Mg}^{2+}$ and $\mathrm{PO}_{4}{ }^{3-}$ in the groundwater and which would almost certainly have a detrimental effect on the health of the people living in the areas concerned, when consumed such water in large quantities. Global changes in $\mathrm{F}^{-}$concentrations in groundwater were studied by Amini et al. (2008) who noted that spatial and temporal heterogeneities of fluoride concentrations in groundwater are large. It is known that fluoride-rich groundwaters are associated with rocks of low $\mathrm{Ca}^{2+}$ contents, high $\mathrm{pH}$ conditions where sodium bicarbonate dominates the groundwater composition. Further, residence time, soil conditions, evapotranspiration and precipitation influence the fluoride concentrations in the groundwater. All these factors are affected by climate change when ambient temperature increases (Watts et al., 2017). The impact of increasing fluoride levels especially in tropical regions is very high leading to fluoride-related diseases (Figure 7).

\section{CONCLUSIONS}

With climate change in tropical countries, the groundwater quality changes frequently due to high evaporation, evapotranspiration, $\mathrm{pH}$ changes and variations in soil chemistry. Fluoride is a chemical species that is found in abundance in the groundwater of tropical regions and medical evidence points to fluoride having a marked effect on human and animal health. Dental and skeletal fluorosis, apatite formation in kidney tubules, calcification of arteries, are such diseases where fluoride plays a major role. Coupled with heat stress caused by increases of global temperature, ionic interactions in groundwater used as a drinking source, precipitation of calcium phosphate nanoparticles takes place aided by nano-bacteria and this could result in kidney diseases in tropical regions. Biomineralogy clearly plays a major role in the new field of Medical Geology. With further advances in instrumentation, notably in transmission electron microscopy, the study of nanocrystal formation in the human body affecting arteries, kidney tubules etc. will almost certainly provide a better understanding of some human diseases.

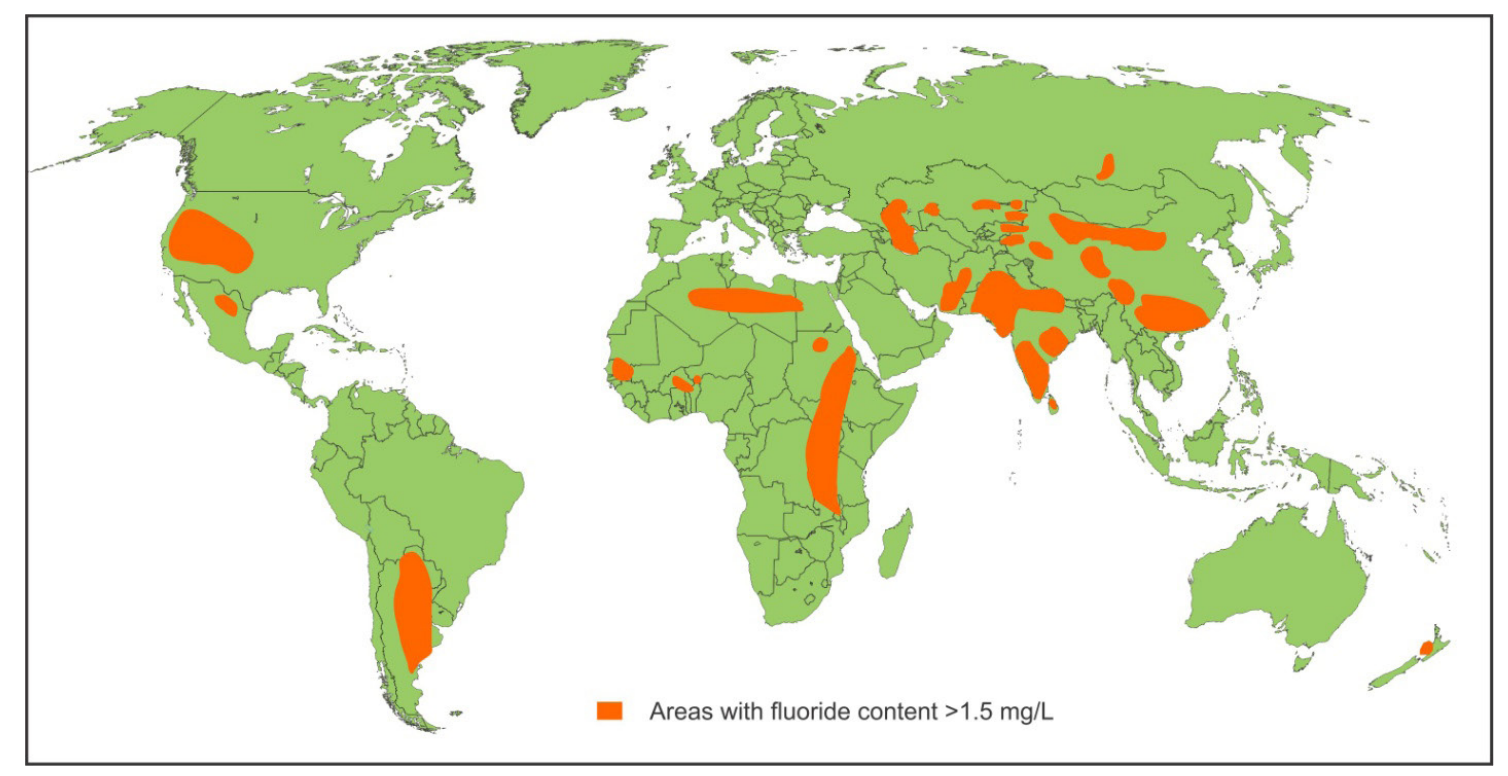

Figure 7: Regions with fluoride concentration in the groundwater exceeding WHO guidelines for drinking water of $1.5 \mathrm{mg} / \mathrm{L}$. 


\section{REFERENCES}

Abeywickarama, B., Ralapanawa, U., and Chandrajith, R. (2016). Geoenvironmental factors related to high incidence of human urinary calculi (kidney stones) in Central Highlands of Sri Lanka. Environmental Geochemistry and Health, 38(5): 1203-1214.

Adriano, D.C. (2001). Trace elements in terrestrial environments. Springer-Verlag New York. pp. 867.

Amini, M., Mueller, K., Abbaspour, K.C., Rosenberg, T., Afyuni, M., Møller, K.N., et al. (2008).Statistical modeling of global geogenic fluoride contamination in groundwaters. Environmental science \& technology 42(10): 3662-3668.

Ando, M., Tadano, M., Yamamoto, S., Tamura, K., Asanuma, S., Watanabe, T., et al. (2001). Health effects of fluoride pollution caused by coal burning. Science of the total environment 271(1-3): 107-116.

Bandara, U.G.C., Diyabalanage, S., Hanke, C., van Geldern, R., Barth, J.A.C., and Chandrajith, R. (2018). Arsenicrich shallow groundwater in sandy aquifer systems buffered by rising carbonate waters: A geochemical case study from Mannar Island, Sri Lanka. Science of the Total Environment 633: 1352-1359. doi: https://doi. org/10.1016/j.scitotenv. 2018.03.226.

Barbier, O., Arreola-Mendoza, L., and Del Razo, L.M. (2010).Molecular mechanisms of fluoride toxicity. Chemico-biological interactions 188(2): 319-333.

Blaine, J., Chonchol, M., and Levi, M. (2014).Renal control of calcium, phosphate, and magnesium homeostasis. Clinical Journal of the American Society of Nephrology, CJN. 09750913.

Chandrajith, R., Abeypala, U., Dissanayake, C.B and Tobshall, H.J ( 2007). Fluoride in tea and itsimplications to dental health. Environmental Geochemitry and Health 29(5): 429-34.

Chandrajith, R., Chaturangani, D., Abeykoon, S., Barth, J.A., van Geldern, R., Edirisinghe, E., et al. (2014). Quantification of groundwater-seawater interaction in a coastal sandy aquifer system: a study from Panama, Sri Lanka. Environmental Earth Sciences 72(3): 867877.

Chandrajith, R., Dissanayake, C.B., Ariyarathna, T., Herath, H., and Padmasiri, J.P. (2011a).Dose-dependent Na and $\mathrm{Ca}$ in fluoride-rich drinking water-Another major cause of chronic renal failure in tropical arid regions. Science of the Total Environment 409(4): 671-675.

Chandrajith, R., Diyabalanage, S., Premathilake, K.M., Hanke, C., van Geldern, R., and Barth, J.A.C. (2016). Controls of evaporative irrigation return flows in comparison to seawater intrusion in coastal karstic aquifers in northern Sri Lanka: Evidence from solutes and stable isotopes. Science of the Total Environment 548: 421-428.

Chandrajith, R., Jayasena, H., van Geldern, R., and Barth, J.A. (2015).Assessment of land subsidence mechanisms triggered by dolomitic marble dissolution from hydrogeochemistry and stable isotopes of spring waters. Applied Geochemistry 58: 97-105.

Chandrajith, R., Nanayakkara, S., Itai, K., Aturaliya, T.N.C., Dissanayake, C.B., Abeysekera, T., et al. (2011b).
Chronic kidney diseases of uncertain etiology (CKDue) in Sri Lanka: geographic distribution and environmental implications. Environmental Geochemistry and Health 33(3): 267-278.

Chandrajith, R., Padmasiri, J.P., Dissanayake, C.B., and Prematilaka, K.M. (2012).Spatial distribution of fluoride in groundwater of Sri Lanka. Journal of the National Science Foundation of Sri Lanka 40(4): 303309

Çiftçioglu, N., Björklund, M., Kuorikoski, K., Bergström, K., and Kajander, E.O. (1999).Nanobacteria: An infectious cause for kidney stone formation. Kidney International 56(5): 1893-1898. doi: https://doi. org/10.1046/j.1523-1755.1999.00755.x.

Cisar, J.O., Xu, D.-Q., Thompson, J., Swaim, W., Hu, L., and Kopecko, D.J. (2000).An alternative interpretation of nanobacteria-induced biomineralization. Proceedings of the National Academy of Sciences 97(21): 1151111515. doi: 10.1073/pnas.97.21.11511.

Cittanova, M.-L., Lelongt, B., Verpont, M.C., GeniteauLegendre, M., Wahbe, F., Prie, D., et al. (1996).Fluoride ion toxicity in human kidney collecting duct cells. Anesthesiology: The Journal of the American Society of Anesthesiologists 84(2): 428-435.

Connett, M. (2012). Fluoride as a cause of kidney disease in humans [Online]. Available: http://fluoridealert.org/ studies/kidney07/ [Accessed 04 August 2018].

Crowe, J., Wesseling, C., Solano, B.R., Umaña, M.P., Ramírez, A.R., Kjellstrom, T., et al. (2013).Heat exposure in sugarcane harvesters in Costa Rica. American journal of industrial medicine 56(10): 11571164.

De Francisco, A.L.M. and Rodríguez, M. (2013). Magnesium - its role in CKD. Nefrologia 33(3): 389399.

Dharma-wardana, M.W.C. (2018).Chronic kidney disease of unknown etiology and the effect of multiple-ion interactions. Environmental Geochemistry and Health 40(2): 705-719.

Dharma-wardana, M.W.C., Amarasiri, S.L., Dharmawardene, N. and Panabokke, C.R. (2015). Chronic kidney disease of unknown aetiology and ground-water ionicity: study based on Sri Lanka. Environmental Geochemistry and Health 37(2): 221231.

Dharmaratne, R.W. (2015). Fluoride in drinking water and diet: the causative factor of chronic kidney diseases in the North Central Province of Sri Lanka. Environmental health and preventive medicine 20(4): 237.

Dissanayake, C.B. (1996). Water quality and dental health in the Dry Zone of Sri Lanka. Geological Society of London, Special Publications 113(1): 131-140.

Dissanayake, C.B. (2005a). Of stones and health: medical geology in Sri Lanka. Science 309(5736), 883-885.

Dissanayake, C.B. (2005b). Water quality in the dry zone of Sri Lanka-some interesting health aspects. Journal of the National Science Foundation of Sri Lanka 33(3): 161-168.

Dissanayake, C.B. and Chandrajith, R. (1999). Medical geochemistry of tropical environments. Earth Science Reviews 47(3): 219-258. 
Dissanayake, C.B., and Chandrajith, R. (2007). Medical geology in tropical countries with special reference to Sri Lanka. Environmental Geochemistry and Health 29(2): 155-162. doi: 10.1007/s10653-006-9070-0.

Dissanayake, C.B. and Chandrajith, R. (2009a). Introduction to medical geology. Springer Science \& Business Media.

Dissanayake, C.B. and Chandrajith, R. (2009b). Phosphate mineral fertilizers, trace metals and human health. Journal of the National Science Foundation (Sri Lanka) 37(3): 153-165.

Dissanayake, C.B. and Chandrajith, R. (2017). Groundwater fluoride as a geochemical marker in the etiology of chronic kidney disease of unknown origin in Sri Lanka. Ceylon Journal of Science 46(2): 3-12

Edmunds, W.M. and Smedley, P.L. (2013). "Fluoride in natural waters," in Essentials of medical geology. Springer 311-336.

Foley, R.N., Parfrey, P.S., and Sarnak, M.J. (1998).Clinical epidemiology of cardiovascular disease in chronic renal disease.American Journal of Kidney Diseases 32(5): S112-S119.

Fyfe, W.S., Kronberg, B.I., Leonardos, O.H. and Olorunfemi, N. (1983). Global tectonics and agriculture: a geochemical perspective. Agriculture, Ecosystems \& Environment 9(4): 383-399.

Glaser, J., Lemery, J., Rajagopalan, B., Diaz, H.F., GarcíaTrabanino, R., Taduri, G., et al. (2016). Climate change and the emergent epidemic of CKD from heat stress in rural communities: the case for heat stress nephropathy. Clinical Journal of the American Society of Nephrology 11(8): 1472-1483.

Harinarayan, C.V., Kochupillai, N., Madhu, S.V., Gupta, N. and Meunier, P.J. (2006). Fluorotoxic metabolic bone disease: an osteo-renal syndrome caused by excess fluoride ingestion in the tropics. Bone 39(4): 907-914.

Herath, H.M.A.S., Kubota, K., Kawakami, T., Nagasawa, S., Motoyama, A., Weragoda, S.K., et al. (2017). Potential risk of drinking water to human health in Sri Lanka. Environmental Forensics 18(3): 241-250.

Kim, S.-H., Kim, K., Ko, K.S., Kim, Y. and Lee, K.S. (2012). Co-contamination of arsenic and fluoride in the groundwater of unconsolidated aquifers under reducing environments. Chemosphere 87(8): 851-856.

Knezović, N.J., Memić, M., Mabić, M., Huremović, J. and Mikulić, I. (2014).Correlation between water hardness and cardiovascular diseases in Mostar city, Bosnia and Herzegovina. Journal of water and health 12(4): 817823.

Lantz, O., Jouvin, M.H., De Vernejoul, M.C. and Druet, P. (1987).Fluoride-induced chronic renal failure. American Journal of Kidney Diseases 10(2): 136-139.

Lapegue, J. (2000). Chemical risks associated to the consumption of groundwater: The specificity of chronic renal failure in eastern areas of Sri Lanka" (Trincomalee, Sri Lanka) Action Contre la Faim Technical Report.

Leurs, L.J., Schouten, L.J., Mons, M.N., Goldbohm, R.A. and van den Brandt, P.A. (2010). Relationship between tap water hardness, magnesium, and calcium concentration and mortality due to ischemic heart disease or stroke in the Netherlands. Environmental health perspectives 118(3): 414-20

Levine, K.E., Redmon, J.H., Elledge, M.F., Wanigasuriya, K.P., Smith, K., Munoz, B., et al. (2016). Quest to identify geochemical risk factors associated with chronic kidney disease of unknown etiology (CKDu) in an endemic region of Sri Lanka-a multimedia laboratory analysis of biological, food, and environmental samples. Environmental Monitoring and Assessment 188(10): 548.

Linnes, M.P., Krambeck, A.E., Cornell, L., Williams Jr, J.C., Korinek, M., Bergstralh, E.J., et al. (2013). Phenotypic characterization of kidney stone formers by endoscopic and histological quantification of intrarenal calcification. Kidney International 84(4): 818-825.

Martel, J., Peng, H.H., Young, D., Wu, C.Y. and Young, J.D. (2014). Of nanobacteria, nanoparticles, biofilms and their role in health and disease: facts, fancy and future. Nanomedicine 9(4): 483-499.

Miller, V.M., Rodgers, G., Charlesworth, J.A., Kirkland, B., Severson, S.R., Rasmussen, T.E., et al. (2004). Evidence of nanobacterial-like structures in calcified human arteries and cardiac valves. American Journal of Physiology-Heart and Circulatory Physiology 287(3): H1115-H1124.

Nanayakkara, S., Stmld, S., Abeysekera, T., Chandrajith, R., Ratnatunga, N., Edl, G., et al. (2014).An integrative study of the genetic, social and environmental determinants of chronic kidney disease characterized by tubulointerstitial damages in the North Central Region of Sri Lanka. Journal of occupational health 56(1): 28-38.

Pauwels, H. and Ahmed, S. (2007). Fluoride in groundwater: origin and health impacts. Géosciences 5: 68-73.

Pauwels, H., Pettenati, M., Perrin, J. and Negrel, P. (Year). "Vulnerability of intensively-exploited hard-rock aquifers to fluoride contamination in India: impact of global change", in: Fourth International Groundwater Conference (IGWC-2011)), 6 p.

Podder, S., Chattopadhyay, A. and Bhattacharya, S. (2011). Reduction in fluoride-induced genotoxicity in mouse bone marrow cells after substituting high fluoride-containing water with safe drinking water. Journal of Applied Toxicology 31(7): 703-705.

Quadri, J.A., Sarwar, S., Sinha, A., Kalaivani, M., Dinda, A.K., Bagga, A., et al. (2018). Fluoride-associated ultrastructural changes and apoptosis in human renal tubule: a pilot study. Human \& experimental toxicology, 0960327118755257.

Rafique, T., Naseem, S., Usmani, T.H., Bashir, E., Khan, F.A. and Bhanger, M.I. (2009).Geochemical factors controlling the occurrence of high fluoride groundwater in the Nagar Parkar area, Sindh, Pakistan. Journal of Hazardous Materials 171(1-3): 424-430.

Ramesam, V. and Rajagopalan, K. (1985). Fluoride ingestion into the natural waters of hard-rock areas, Peninsular India. Journal of the Geological Society of India 26(2), 125-132.

Rango, T., Jeuland, M., Manthrithilake, H. and McCornick, P. (2015). Nephrotoxic contaminants in drinking water 
and urine, and chronic kidney disease in rural Sri Lanka. Science of the Total Environment 518-519: 574-585. doi: http://doi.org/10.1016/j.scitotenv.2015.02.097.

Robertson, W.G. (2015). Potential role of fluctuations in the composition of renal tubular fluid through the nephron in the initiation of Randall's plugs and calcium oxalate crystalluria in a computer model of renal function. Urolithiasis 43(1): 93-107.

Roncal-Jimenez, C., García-Trabanino, R., Barregard, L., Lanaspa, M.A., Wesseling, C., Harra, T., et al. (2016). Heat Stress Nephropathy From Exercise-Induced Uric Acid Crystalluria: A Perspective on Mesoamerican Nephropathy. American Journal of Kidney Diseases 67(1), 20-30. doi: https://doi.org/10.1053/j. ajkd.2015.08.021.

Rubasinghe, R., Gunatilake, S.K. and Chandrajith, R. (2015).Geochemical characteristics of groundwater in different climatic zones of Sri Lanka. Environmental Earth Sciences 74(4): 3067-3076.

Rylander, R., Bonevik, H. and Rubenowitz, E. (1991). Magnesium and calcium in drinking water and cardiovascular mortality. Scandinavian journal of work, environment \& health, 91-94.

Sivasankar, V., Darchen, A., Omine, K. and Sakthivel, R. (2016). "Fluoride: A world ubiquitous compound, its chemistry, and ways of contamination," in Surface modified carbons as scavengers for fluoride from water. Springer 5-32.

Thole, B. (2011). Defluoridation kinetics of 200C calcined bauxite,gypsum and magnesite and breakthrough characteristics of their composite filter. Journal of Fluorine Chemistry 132:529-535.

Wasana, H.M.S., Aluthpatabendi, D., Kularatne, W.M.T.D., Wijekoon, P., Weerasooriya, R. and Bandara, J. (2016). Drinking water quality and chronic kidney disease of unknown etiology $(\mathrm{CKDu})$ : synergic effects of fluoride, cadmium and hardness of water. Environmental Geochemistry and Health 38(1): 157-168. doi: 10.1007/ s10653-015-9699-7.
Watts, N., Adger, W.N., Ayeb-Karlsson, S., Bai, Y., Byass, P., Campbell-Lendrum, D., et al. (2017). The Lancet Countdown: tracking progress on health and climate change. The Lancet 389(10074): 1151-1164.

Wickramarathna, S., Balasooriya, S., Diyabalanage, S. and Chandrajith, R. (2017). Tracing environmental aetiological factors of chronic kidney diseases in the dry zone of Sri Lanka-A hydrogeochemical and isotope approach. Journal of Trace Elements in Medicine and Biology 44: 298-306. doi: https://doi.org/10.1016/j. jtemb.2017.08.013.

Wong, T.Y., Wu, C.Y., Martel, J., Lin, C.W., Hsu, F.Y., Ojcius, D.M., et al. (2015). Detection and characterization of mineralo-organic nanoparticles in human kidneys. Scientific Reports 5, 15272.doi: 10.1038/srep15272.

Xiong, X.Z., Liu, J.L., He, W.H., Xia, T., He, P., Chen, X.M., et al. (2007). Dose-effect relationship between drinking water fluoride levels and damage to liver and kidney functions in children. Environmental Research 103(1): 112-116.

Yang, C.-Y.(1998). Calcium and magnesium in drinking water and risk of death from cerebrovascular disease. Stroke 29(2): 411-414.

Yang, Y., Deng, Y. and Wang, Y. (2016). Major geogenic factors controlling geographical clustering of urolithiasis in China. Science of the total environment 571: 1164-1171.

Yiu, A.J., Callaghan, D., Sultana, R. and Bandyopadhyay, B.C. (2015). Vascular calcification and stone disease: a new look towards the mechanism. Journal of cardiovascular development and disease 2(3): 141-164.

Zager, R.A. and Iwata, M. (1997).Inorganic fluoride. Divergent effects on human proximal tubular cell viability. The American journal of pathology 150(2): 735.

Zhang, Y. and Cremer, P.S. (2006). Interactions between macromolecules and ions: the Hofmeister series. Current opinion in chemical biology 10(6): 658-663. 